\title{
Safe staffing
}

\author{
Fiona Godlee editor in chief
}

The BMJ

How many doctors does it take to staff a hospital? This might seem a simple question, but even asking it seems brave to some. What if the answer shows how few hospitals have safe medical cover? After the scandal of Mid Staffordshire, Robert Francis called on the National Institute for Health and Clinical Excellence to draw up safe staffing levels, to be policed by the Care Quality Commission. NICE has produced guidelines for the number of nurses needed but not for doctors.

The Royal College of Physicians has now taken up this challenge. As Matthew Limb reports (doi:10.1136/bmj.k3136), the college's review, summarised in our accompanying infographic, gives indicative figures for how many person hours for junior, middle ranking, and senior doctors are needed in the assessment and admissions team, on a medical ward in the week and at weekends, and for day and night on-call cover in different sized hospitals. Where possible, the college has suggested the number of posts needed to cover these hours; crucially, these estimates recognise that doctors take annual, study, and sick leave. This basic fact hasn't been properly accounted for in the past, says the college's president elect, Andrew Goddard. And as for the cost of proper staffing, let's not forget that the NHS spent £3bn (€4.4bn; \$4bn) last year on locums. "The NHS already spends a lot of money trying to fill rota gaps and shortages and a lot of money trying to sort out problems when something's gone wrong with patient care that could be prevented by having adequate staffing levels."

The UK has fewer doctors and nurses per head of population than similar economies in Europe, write Azeem Majeed and colleagues (doi:10.1136/bmj.k3036). Tackling staff shortages will be key to improving outcomes in the NHS, they say. So too will integrating general practice and specialist services within one organisation, providing a single point of contact for urgent care, investing in specialty services, and improving the use of digital technology. And then there is the need to consider the wider determinants of health: housing, education, employment, and the environment. These social inequalities drive poorer outcomes, especially in children and elderly people, they say.

Few people have done more to highlight the effects of social inequality on health than Julian Tudor Hart, who died earlier this month (doi:10.1136/bmj.k3052). His lasting contribution was the "inverse care law," the idea that the people who most need good medical care are the least likely to get it. It also says that this effect is strongest where medical care is most exposed to market forces and weakest where this exposure is reduced. As we ponder the future of the NHS, we would do well to remember this. 